\title{
Meconium Evacuation for Facilitating Feed Tolerance in Preterm Neonates: A Systematic Review and Meta-Analysis
}

\author{
Mangesh Deshmukha,b Hari Balasubramanian ${ }^{c}$ Sanjay Patole ${ }^{c}$ \\ aDepartment of Neonatology, St. John of God Hospital, 'bepartment of Neonatal Paediatrics, Fiona Stanley Hospital, \\ and ${ }^{\mathrm{C}}$ Department of Neonatal Paediatrics, King Edward Memorial Hospital, Perth, W.A., Australia
}

\section{Key Words}

Preterm infant · Meconium · Suppositories · Enema ·

Feed intolerance

\begin{abstract}
Background: A delayed passage of meconium is considered as a risk factor for feed intolerance in preterm neonates. $\mathbf{O b}$ jectives: The aim of this study was to review the effects of different therapeutic agents for meconium evacuation on feed tolerance in preterm neonates. Methods: A systematic review of randomised controlled trials (RCTs) of different therapeutic agents for meconium evacuation in preterm neonates (gestation $<32$ weeks and/or birth weight $<1,500 \mathrm{~g}$ ) using the Cochrane systematic review methodology was undertaken. Databases including GoogleScholar were searched in January 2016. The primary outcome was the time to reach full feeds (TFF; $\geq 120 \mathrm{ml} / \mathrm{kg}$ feeds with stoppage of parenteral nutrition $>24 \mathrm{~h}$ ). Secondary outcomes included necrotising enterocolitis (NEC), weight at discharge and adverse effects. The results were summarised as per the GRADE guidelines. Results: Six RCTs (2 each of glycerine suppository and enema, 1 normal saline enema and 1 oral osmotic contrast agent; $n=442$ ) with a low or unclear risk of bias were included. The pooled estimate (random effects model) showed no reduction in TFF [mean difference (MD) -0.03 ,
\end{abstract}

95\% Cl-2.47, 2.41, p = 0.98; level of evidence: low]. No differences in NEC [risk ratio (RR) 1.71, 95\% Cl 0.63, 4.65, p = 0.30; level of evidence: low] and weight at discharge (MD -0.08, $95 \% \mathrm{Cl}-0.30,0.15, \mathrm{p}=0.50$; level of evidence: low) were found. The trial assessing oral osmotic contrast agents reported a trend towards a higher incidence of NEC $\geq$ stage II. There were no other adverse effects. Conclusion: Limited low-quality evidence indicates that prophylactic glycerine suppository, small volume glycerine/normal saline enema or oral osmotic contrast agents to evacuate meconium did not reduce TFF in preterm neonates. Large, well-designed trials are essential to study this clinically significant issue.

(c) 2016 S. Karger AG, Basel

\section{Introduction}

Recent advances in neonatal care have improved the survival of preterm very low birth weight (VLBW) neonates. Suboptimal nutrition is linked with adverse developmental outcomes in this population of high-risk neonates [1]. Optimising enteral nutrition is challenging in preterm VLBW neonates due to feed intolerance that relates to the immaturity of gastrointestinal motility and poor coordinated peristalsis [2-5]. Feed intolerance is associated with prolonged dependence on parenteral nutri-

\section{KARGER}

E-Mail karger@karger.com

www.karger.com/neo
(C) 2016 S. Karger AG, Basel

1661-7800/16/1101-0055\$39.50/0
Mangesh Deshmukh, FRACP, MSC

St. John of God Hospital

12 Salvado Road

Subiaco, WA 6008 (Australia)

E-Mail mangesh.deshmukh@ @ealth.wa.gov.au 
tion and its complications (e.g. sepsis, cholestasis) and delayed maturation of gut function [6-9]. The use of medications such as prokinetics (e.g. erythromycin, cisapride) to improve gut motility has failed to show significant benefits in VLBW neonates and is associated with adverse effects $[10,11]$.

A delayed passage of meconium is identified as one of the risk factors for feed intolerance in preterm VLBW neonates [12]. Mihatsch et al. [12] evaluated the correlation between the timing of the first and last meconium passage and feeding tolerance in VLBW neonates, and demonstrated that rapid evacuation of meconium was associated with improved feed tolerance during first 14 days of life. Glycerine suppositories are often used to facilitate meconium evacuation in many neonatal units [13]. Glycerine acts as a lubricant and a rectal stimulant due to the mildly irritant action of glycerol [14]. A survey of enteral feeding practises among Australian neonatologists showed that the use of glycerine suppositories (sometimes $30.9 \%$, often $9.1 \%$, always $3.6 \%$ ) and prokinetics (sometimes $25.9 \%$, often $5.6 \%$, always $0 \%$ ) was not uncommon to improve feed tolerance [13]. An observational study by Shim et al. [5] reported benefits of meconium evacuation by glycerine enema in achieving earlier full enteral feeds (hazard ratio $2.9,95 \% \mathrm{CI} 1.8,4.8$ ) and reducing the incidence of line sepsis in VLBW neonates. So far all reviews on the topic of meconium evacuation in preterm neonates are limited to the use of either a glycerine suppository or enema [15-17]. Considering these data and the significance of optimising enteral nutrition in preterm VLBW neonates, we aimed to conduct a systematic review of studies reporting the effects of different therapeutic agents for meconium evacuation on feed tolerance in this population.

\section{Methods}

The Cochrane methodology and PRISMA guidelines (online suppl. material; see www.karger.com/doi/10.1159/000444075 for all online suppl. material) were used for conducting and reporting this systematic review, respectively $[18,19]$. Ethics approval was not required.

\section{Eligibility Criteria}

Randomised controlled trials (RCTs) and quasi-RCTs were eligible for inclusion. Non-RCTs, reviews and commentaries were excluded, but read to identify other potential studies.

\section{Participants and Types of Intervention}

Inclusion criteria were neonates born $\leq 32$ weeks of gestation and/or with a birth weight $<1,500 \mathrm{~g}$. The exclusion criteria were based on major chromosomal and congenital anomalies. Within the studies, meconium evacuation with any therapeutic agent (e.g. rectal suppository or small volume enema) versus control represented the types of intervention of interest.

\section{Types of Outcome}

The primary outcome was the time to reach full feeds (TFF), defined as enteral feeds $\geq 120 \mathrm{ml} / \mathrm{kg}$ or full feeds with stoppage of parenteral nutrition $>24 \mathrm{~h}$. Secondary outcomes included the following: (1) necrotising enterocolitis (NEC; $\geq$ stage II) [20], (2) mortality, (3) duration of hospital stay, (4) weight at discharge, (5) rectal bleeding, (6) perforation and (7) other adverse effects, e.g. vomiting, dehydration.

\section{Search Strategy}

We searched MEDLINE (from 1966), EMBASE (from 1980), CINAHL and the Cochrane Central Register of Controlled Trials in December 2014 for published studies, and updated the searches in January 2016. We used the following search terms in various combinations: (a) population: neonate(s), newborn(s), infant*, premature, very low birth weight(s); (b) intervention: meconium (subject heading) OR meconium*, enema*, glycerol, suppositories*, laxative; (c) outcome-feed*, feed intolerance, nutritional intolerance, enteric feeding, enteral nutrition. We restricted our search to publication type 'randomized controlled trial', 'controlled trial' or 'clinical trial'. Online abstracts of Pediatric Academic Society (PAS) meetings were reviewed from 2002. Abstracts of conference proceedings including the Perinatal Society of Australia and New Zealand (PSANZ), European Academy of Paediatric Societies, and the British Maternal and Fetal Medicine Society were searched in EMBASE. Google Scholar was searched for articles that might not have been cited in the standard medical databases. The reference lists of identified studies and review articles were searched to identify additional eligible studies. We also searched www.clinicaltrials.gov and the Australian New Zealand trial registry (www.anzctr.org.au) for ongoing studies. No language restriction was applied. Reviewers M.D. and H.B. conducted the literature search independently.

\section{Study Selection}

The abstracts of the citations obtained from the initial broad search were read independently by reviewers M.D. and H.B. to identify potentially eligible studies. Full-text articles of these studies were obtained and assessed independently by reviewers M.D. and H.B. for eligibility using the predefined eligibility criteria. Differences in opinion were resolved by group discussion among all reviewers to reach a consensus. Multiple publications of the same study were identified and excluded to avoid duplication of the data.

\section{Data Extraction}

Reviewers M.D. and H.B. extracted the data independently using a data collection form designed for this review. For dichotomous outcomes, the number of patients with the event and the number of patients analysed in each treatment group of each trial were entered into the form. For continuous outcomes we planned to enter the mean and standard deviations. Information about study design and outcomes were verified by all reviewers. Discrepancies during the data extraction process were resolved by discussion and consensus among all reviewers. We contacted authors for additional information/clarifications when details were not available in the published manuscripts. 
Fig. 1. Flow chart of the study selection process after screening of the electronic search.

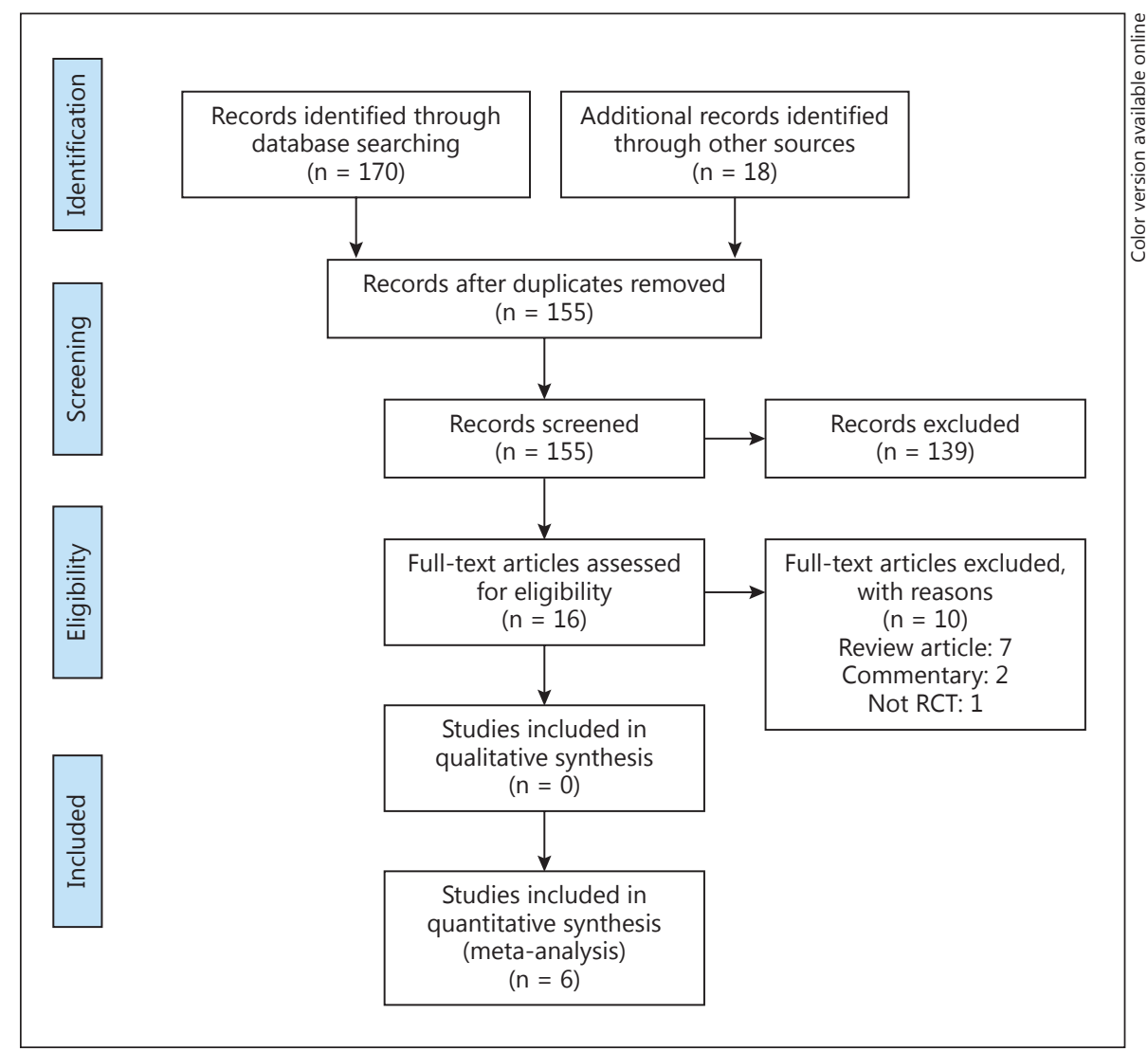

Risk of Bias Assessment

The risk of bias was assessed using the Cochrane 'Risk of Bias Assessment Tool' [21]. Two authors (M.D. and H.B.) independently assessed the risk of bias in the domains of random number generation, allocation concealment, blinding of participants and outcome assessors, completeness of follow-up, selective reporting and other biases. The studies were assigned as of high, low or unclear risk of bias. Difference of opinion was resolved by group discussion to reach a consensus.

\section{Data Synthesis}

A meta-analysis was conducted using Review Manager 5.3 (Cochrane Collaboration, Nordic Cochrane Centre), with 'intention to treat analysis' of the data. We used a random-effects model assuming wide heterogeneity. The categorical measure of effect size was expressed as the risk ratio (RR; Mantel-Haenszel method), and the mean difference (MD; inverse variance method) was used for continuous measures. Statistical heterogeneity was assessed using the $\chi^{2}$ test, $\mathrm{I}^{2}$ statistic, and by visual inspection of the forest plot (overlap of confidence intervals). The risk of publication bias was intended to be assessed by a funnel plot [22].

\section{Summary of Findings}

Data concerning the quality of evidence, the magnitude of effect of the intervention, and the sum of available data on the main outcomes were presented in the 'summary of findings table' as per the GRADE (the grading of recommendations assessment, devel-

Meconium Evacuation for Facilitating

Feed Tolerance in Preterm Neonates opment and evaluation) guidelines [23]. The domains of risk of bias, inconsistency or heterogeneity of evidence, indirectness of evidence, imprecision of results and publication bias were included.

\section{Results}

The databases and Google Scholar search retrieved 188 potentially relevant citations (fig. 1). A total of 16 studies were read in detail. We identified 7 studies that assessed interventions to evacuate meconium. The observational study by Shim et al. [5] $(\mathrm{n}=83)$ was excluded from the final analysis. Thus, a total of 6 studies $(n=442)$ assessing different interventions (glycerine suppository/enema, saline enema, oral osmotic contrast agent) for meconium evacuation were eligible for inclusion in the analysis [2429]. The characteristics of these studies are shown in table 1. The risk of bias in these studies was low or unclear (fig. 2). Four of the 6 studies had TFF as the primary outcome $[24,26,27,29]$, and those by Haiden et al. [25] and Saenz de Pipaón Marcos et al. [28] had TFF as the secondary outcome. We used the method of Hozo et al. [30] to 
Table 1. Characteristics of the included studies

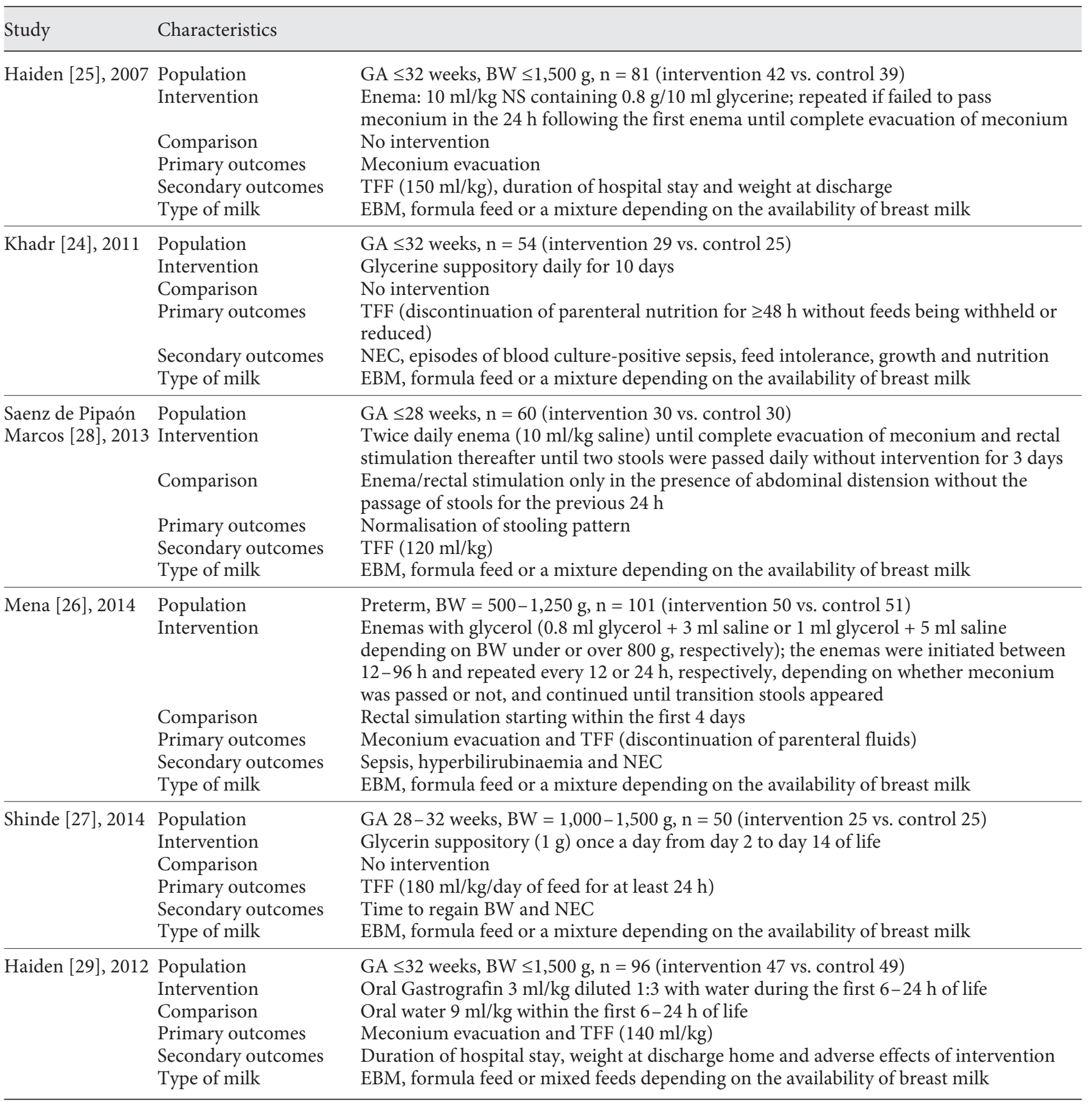

$\mathrm{GA}=$ Gestational age; $\mathrm{BW}=$ birth weight; $\mathrm{NS}=$ normal saline .

derive the mean and standard deviation from the median and range reported in the original article. For the purpose of the meta-analysis we divided the studies according to mode of intervention (rectal or oral).

\section{Details of the Included Studies}

In a double-blind RCT by Shinde et al. [27], preterm neonates (gestation 28-32 weeks, birth weight 1,000$1,500 \mathrm{~g}$ ) were randomised to receive glycerine supposi- 
tory $(1 \mathrm{~g} /$ day $)$ or a sham procedure from day 2 to 14 . All received either expressed breast milk (EBM) or formula feeds. The primary outcome was TFF (tolerating $180 \mathrm{ml} /$ $\mathrm{kg} /$ day of feed for at least $24 \mathrm{~h}$ ). Secondary outcomes included the time to regain birth weight and NEC.

Khadr et al. [24] performed a non-blinded trial where preterm neonates ( $<32$ weeks) were randomised to a glycerine suppository ( $250-500 \mathrm{mg} /$ day) or no intervention from $24 \mathrm{~h}$ of age until day 10 . All neonates received either EBM, formula or a mixture depending on breast milk availability. A standardised feeding protocol was used. The primary outcome was TFF defined as the tolerance of full enteral feeds and discontinuation of parenteral nutrition for $\geq 48 \mathrm{~h}$ without feeds being withheld or reduced. Secondary outcomes included NEC, episodes of blood culture-positive sepsis, feed intolerance, growth and nutrition.

In a study by Haiden et al. [25], preterm neonates ( $\leq 32$ weeks, birth weight $\leq 1,500 \mathrm{~g}$ ) who did not pass meconium during the first $12 \mathrm{~h}$ of life were randomised to receive repeated glycerine enema $(10 \mathrm{ml} / \mathrm{kg}$ normal saline containing $0.8 \mathrm{~g} / 10 \mathrm{ml}$ ) or no intervention. Repeat enema was administered if the neonate failed to pass meconium in the $24 \mathrm{~h}$ following the first enema, which was subsequently continued until the complete evacuation of meconium. All neonates received either EBM, formula or mix feeds depending on breast milk availability. A standardised feeding protocol was used. The primary outcome was the time when the last meconium was passed. Secondary outcomes were TFF $(150 \mathrm{ml} / \mathrm{kg})$, the duration of hospital stay and weight at discharge.

Mena et al. [26] reported a 3-centre trial carried out in South America. Neonates (birth weight 500-1,250 g) were randomised to enemas with glycerol $(0.8 \mathrm{ml}$ glycerol $+3 \mathrm{ml}$ saline or $1 \mathrm{ml}$ glycerol $+5 \mathrm{ml}$ saline depending on birth weight being under or over $800 \mathrm{~g}$, respectively) versus rectal stimulation starting within the first 4 days. The enemas were initiated between 12 and $96 \mathrm{~h}$ and repeated every 12 or $24 \mathrm{~h}$, respectively, depending on whether meconium was passed or not, and continued until transition stools appeared. A standardised feeding protocol was used. The primary outcome was meconium evacuation and TFF (discontinuation of parenteral fluids). The secondary outcomes included sepsis, hyperbilirubinaemia and NEC.

In a second study by Haiden et al. [29], preterm neonates ( $<32$ weeks, $<1,500 \mathrm{~g}$ ) were randomised to oral Gastrografin $(3 \mathrm{ml} / \mathrm{kg}$, diluted 1:3 with water, total $9 \mathrm{ml} / \mathrm{kg})$ or an equal volume of water via the gastric tube within the first 6-24 h of life. All subjects received either EBM, for-

Meconium Evacuation for Facilitating

Feed Tolerance in Preterm Neonates

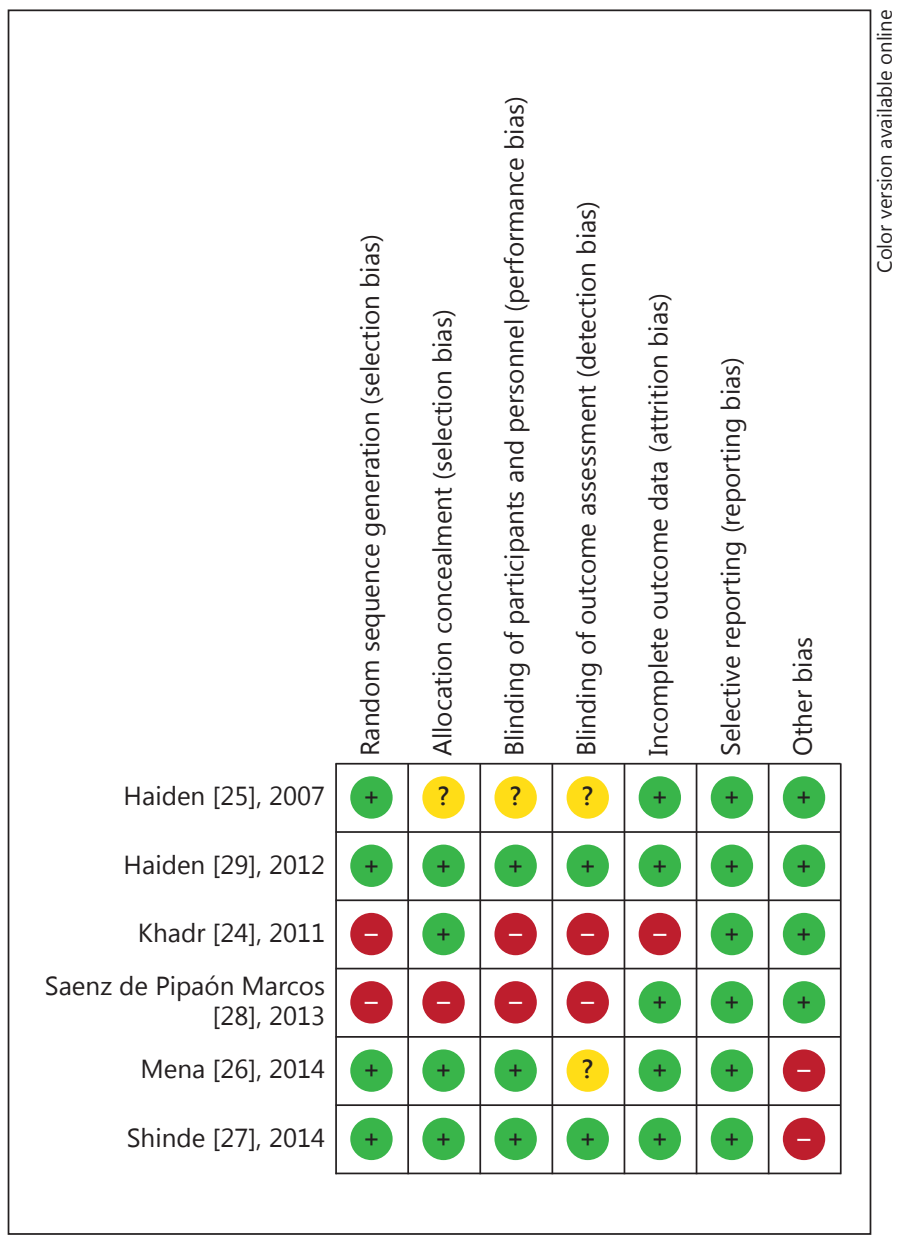

Fig. 2. Summary of the risk of bias for included studies.

mula feeds or mixed feeds depending on the availability of breast milk. A standardised feeding protocol was used. The primary outcomes were the time when the last meconium was passed and TFF ( $140 \mathrm{ml} / \mathrm{kg})$. Secondary outcomes included the duration of hospital stay, weight at discharge home and adverse effects of the intervention.

Saenz de Pipaón Marcos et al. [28] considered neonates born at $\leq 28$ weeks of gestation that were randomised to either the intervention or control group. Intervention consisted of the following: twice daily enema (10 $\mathrm{ml} / \mathrm{kg}$ saline) until the complete evacuation of meconium and rectal stimulation thereafter until two stools were passed daily without intervention for 3 days. Control group neonates received enema/rectal stimulation only in cases of abdominal distension without the passage of stools for the previous $24 \mathrm{~h}$. All neonates received either EBM, formula feeds or a mixture depending on the 


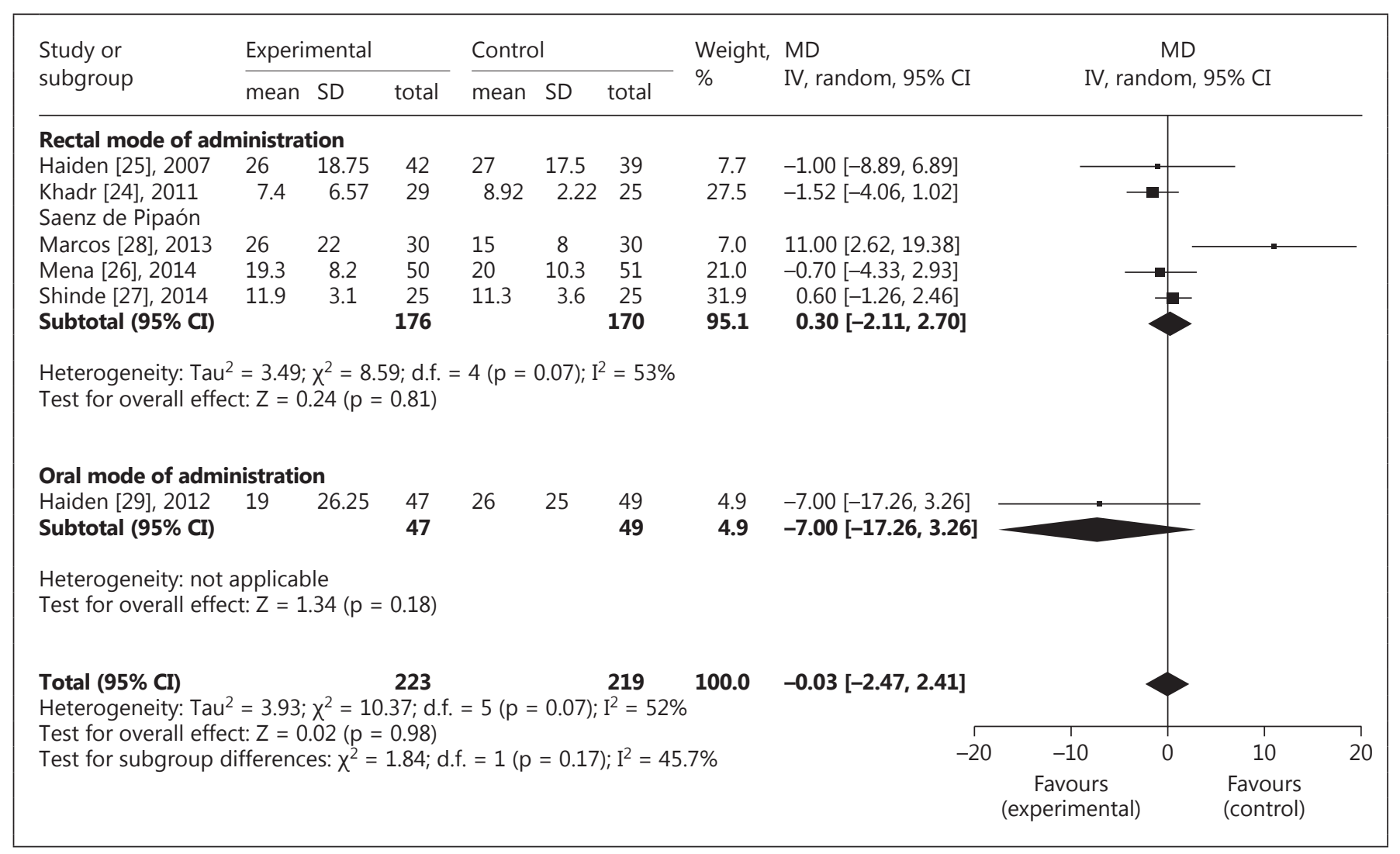

Fig. 3. Effect of meconium evacuation on TFF.

availability of breast milk. A standardised feeding protocol was used. The primary outcome was the time to a normal stooling pattern. The secondary outcome was TFF $(120 \mathrm{ml} / \mathrm{kg})$.

\section{Primary Outcome}

All six studies reported TFF as the primary outcome $(\mathrm{n}=442)$. None of the individual studies demonstrated a statistically significant reduction in TFF. Haiden et al. [29] noted a trend towards reduced TFF in the oral Gastrografin group [median (range) $26(9-109)$ vs. 19 (10115 ) days, $p=0.15]$. Saenz de Pipaón Marcos et al. [28] found significantly increased TFF in the intervention versus control group [26 (21) vs. 15 (8) days, $\mathrm{p}=0.005$ ], but the regression analysis showed that patent ductus arteriosus rather than enema and rectal stimulation was significantly associated with an increased TFF. Results from the other studies [Haiden et al. [25]: 26 (8-83) vs. 27 (5-75) days, $\mathrm{p}=0.91$; Mena et al. [26]: 19.3 (8.2) vs. 20 (10.3) days; Khadr et al. [24]: 7.4 (4.6-30.9) vs. 9 (4.4-13.3) days, $\mathrm{p}=0.78$, and Shinde et al. [27]: 11.9 (3.1) vs. 11.3 (3.6) days] did not show any difference in TFF in the intervention versus control groups [24-27].

The overall pooled estimate suggested that various strategies used for meconium evacuation did not reduce TFF (MD -0.03, 95\% CI -2.47, 2.41, p = 0.98; heterogeneity: $\chi^{2}=10.37, \mathrm{I}^{2}=52 \%$; fig. 3 ). The subgroup analysis showed no difference in TFF irrespective of an oral or rectal mode of intervention.

\section{Secondary Outcomes}

All 6 studies reported the outcome of NEC $\geq$ stage II $(\mathrm{n}=442)$. Overall, $12 \%$ of neonates in the intervention group and 7\% in the control group developed NEC. None of the individual studies showed any statistically significant increase in the risk of NEC in the intervention versus control arm, even though Haiden et al. [29] and Saenz de Pipaón Marcos et al. [28] noted an increased trend towards NEC in the intervention group. The former showed a statistically non-significant increase in NEC ( 21 vs. $8 \%$ ) in the Gastrografin group, the latter showed a similar statistically non-significant increase in NEC (23 vs. $3 \%)$ in 
Table 2. Summary of findings for pooled data as per the GRADE guidelines [23]

\begin{tabular}{|c|c|c|c|c|c|c|}
\hline Outcome & $\begin{array}{l}\text { estimated risk in } \\
\text { control group }\end{array}$ & $\begin{array}{l}\text { corresponding risk in } \\
\text { intervention group }\end{array}$ & Relative effect (95\% CI) & $\begin{array}{l}\text { Partici- } \\
\text { pants, } n\end{array}$ & $\begin{array}{l}\text { Quality of } \\
\text { evidence } \\
\text { grade }\end{array}$ & Comment \\
\hline TFF & Mean 8-27 days & $\begin{array}{l}\text { Mean } 0.03 \text { days lower } \\
(-2.47 \text { to } 2.41)\end{array}$ & MD -0.03 (-2.47, 2.41) & 442 & Low & $\begin{array}{l}\text { Small sample } \\
\text { size }\end{array}$ \\
\hline Mortality & $22 / 180(12.2 \%)$ & $24 / 181(13.2 \%)$ & RR $1.08(0.63,1.85)$ & 361 & Low & $\begin{array}{l}\text { Small sample } \\
\text { size and het- } \\
\text { erogeneity }\end{array}$ \\
\hline Hospital stay & Mean 48-85 days & $\begin{array}{l}\text { Mean } 0.91 \text { days lower } \\
(-10.28 \text { to } 8.47)\end{array}$ & $\mathrm{MD}-0.91(-10.28,8.47)$ & 281 & Low & $\begin{array}{l}\text { Small sample } \\
\text { size and het- } \\
\text { erogeneity }\end{array}$ \\
\hline
\end{tabular}

control groups. Haiden et al. [29] noted no difference between the intervention and control group [median (range) 61 (4-209) vs. 70 (4-179) days, $\mathrm{p}=0.35$ ]. In their earlier study, Haiden et al. [25] also noted no difference between the intervention and control groups [90 (65$140)$ vs. 85 (55-168) days, $\mathrm{p}=0.66$ ]. Similarly, Khadr et al. [24] [60.5 (26-222) vs. $80(29-143)$ days, $p=0.275$ ] and Shinde et al. [27] [mean (SD) 53.7 (14.4) vs. 48.9 (14.8)] showed no difference between the intervention and control groups. The pooled results suggested no effect of intervention on the duration of hospital stay (MD $-0.91,95 \%$ CI $-10.28,8.47, \mathrm{p}=0.85$; heterogeneity: $\chi^{2}=$ $\left.6.05 ; \mathrm{I}^{2}=50 \%\right)$.

Only 3 out of the 6 studies reported weight at discharge as an outcome. Haiden et al. [25, 29] failed to show any statistically significant difference in weight at discharge [median (range) $2.013(1.64-3.6)$ vs. $2.075(1.43-4.13) \mathrm{kg}$, $\mathrm{p}=0.54$, and $2.27(1.65-6.72)$ vs. $2.38(1.61-4.65) \mathrm{kg}, \mathrm{p}=$ 0.64, respectively]. Saenz de Pipaón Marcos et al. [28] reported statistically significant lower weight $\mathrm{z}$ scores at 36 weeks corrected gestational age in the intervention versus control groups [mean (SD): $-2.2(0.7)$ vs. $-1.4(0.7), \mathrm{p}<$ 0.05]. However no suitable data was available for the meta-analysis. The pooled estimate based on the studies by Haiden et al. $[25,29]$ suggested no difference in weight at discharge between the intervention and control groups $(\mathrm{n}=177 ; \mathrm{MD}-0.08,95 \% \mathrm{CI}-0.30,0.15, \mathrm{p}=0.50$; heterogeneity: $\left.\chi^{2}=0.04 ; \mathrm{I}^{2}=0 \%\right)$.
Considering other secondary outcomes, Haiden et al. $[25,29]$, Khadr et al. [24] and Shinde et al. [27; pers. commun.] reported no rectal perforation and no rectal bleeding secondary to the intervention. For other adverse effects, Haiden et al. [29] reported a high proportion of NEC $\geq$ stage II ( 21 vs. $8 \%$ ), vomiting, nausea and bradycardia in neonates in the Gastrografin group [29]. None of the studies reported dehydration or any further adverse effects.

\section{Grading of Evidence and Summary of Findings}

The overall evidence was deemed to be of low quality considering the small sample sizes and heterogeneity in the included studies, as per GRADE guidelines [23] (table 2). We did not assess publication bias as the number of studies was too small [31].

\section{Discussion}

The results of our systematic review suggest that the use of a glycerine suppository, small-volume enema with glycerine or normal saline, or the administration of an oral osmotic agent, such as Gastrografin, to evacuate the meconium did not reduce the time to reach full enteral feeds in preterm VLBW neonates. These findings are not unexpected as normal function of the upper as well as lower gastrointestinal tract is essential for the complete 
Table 3. Ongoing studies evaluating the effects of meconium evacuation on feed tolerance

\begin{tabular}{|c|c|c|c|c|c|}
\hline Study & $\begin{array}{l}\text { Inclusion } \\
\text { criteria }\end{array}$ & $\begin{array}{l}\text { Sample } \\
\text { size, } \mathrm{n}\end{array}$ & Intervention & $\begin{array}{l}\text { Primary } \\
\text { outcome }\end{array}$ & Status \\
\hline $\begin{array}{l}\text { Glycerine suppositories used prophylactically in } \\
\text { premature infants (SUPP): a pilot randomised } \\
\text { placebo-controlled trial (NCT02153606) }\end{array}$ & $\begin{array}{l}\text { GA } 24-32 \text { weeks } \\
\text { BW } 500-1,500 \mathrm{~g}\end{array}$ & 30 & $\begin{array}{l}\text { Glycerine suppository } \\
\text { vs. sham suppository }\end{array}$ & $\begin{array}{l}\text { Time to reach } \\
150 \mathrm{ml} / \mathrm{kg} \text { feeds }\end{array}$ & $\begin{array}{l}\text { Start: January } 2015 \\
\text { Estimated completion } \\
\text { date: June 2015, results } \\
\text { are expected to be } \\
\text { available in } 2016\end{array}$ \\
\hline $\begin{array}{l}\text { The effect of early aggressive meconium evacuation } \\
\text { on duration to reach full oral feeds in VLBW } \\
\text { infants: a randomised control trial comparing } \\
\text { regular daily saline rectal washout with conventional } \\
\text { management using glycerine suppositories } \\
\text { (ACTRN12614000128695) }\end{array}$ & BW $750-1,500 \mathrm{~g}$ & 60 & $\begin{array}{l}\text { Rectal washout with } \\
\text { normal saline }(20 \mathrm{ml} / \\
\mathrm{kg} \text { twice a day) vs. } \\
\text { glycerine suppository } \\
(1 / 4) \text { if baby fails to } \\
\text { pass meconium in } 48 \mathrm{~h}\end{array}$ & $\begin{array}{l}\text { Time until } 2 \\
\text { days of yellow } \\
\text { stools or } \geq 110 \\
\mathrm{ml} / \mathrm{kg} / \text { day of } \\
\text { feeds, which- } \\
\text { ever is earlier }\end{array}$ & $\begin{array}{l}\text { Start: November, } 2013 \\
\text { Still recruiting }\end{array}$ \\
\hline
\end{tabular}

Sources: www.clinicaltrials.gov; www.anzctr.org.au. GA = Gestational age; BW = birth weight.

evacuation of meconium and feed tolerance. Interventions such as a glycerine suppository or small-volume enemas do not have an effect on the right colon or the small bowel [12]. Preterm VLBW neonates have poor gastroduodenal coordination with excessive quiescence in motor activity as well as delayed and slow colonic motility; together these may play an important role in a delayed stooling pattern and feed intolerance [32]. Gastric aspirates reflect poor gastric emptying, gastroduodenal hypomotility and duodeno-gastric reflux [32]. The gastro-anal transit time is significantly longer in preterm neonates as small bowel motility is poorly developed, especially before 28 weeks $[33,34]$.

Our findings are in line with previous systematic reviews on this topic which also suggested no significant advantage of glycerine suppositories or enema for meconium evacuation to reduce feed intolerance [15-17]. Our review is comprehensive in that it evaluates all therapeutic agents for meconium evacuation regardless of their route of administration. The limitations include the small sample size, inherent bias due to a lack of blinding of the intervention in some studies, and lack of a standard definition for TFF. The milk type may also have an effect on feed tolerance and TFF in preterm neonates. However, none of the studies had subgrouped the data according to milk type. The external validity of our results may be difficult to assess as the frequency of administration of suppositories/enemas, etc. to aid the passage of meconium is expected to vary significantly.

Meconium Evacuation for Facilitating

Feed Tolerance in Preterm Neonates
It is important to consider the adverse effects of interventions for meconium evacuation in preterm neonates. Enteral administration of hyperosmolar agents (e.g. 1:3 diluted Gastrografin $=717 \mathrm{mosm} / \mathrm{l}$ ) has the potential to stimulate both the upper as well as the lower gastrointestinal tract. However, their use may not be without risk as the recommended osmotic load cut-offs for enteral feeds in preterm neonates is $450 \mathrm{mosm} / \mathrm{l}[35,36]$. Hyperosmolar contrast agents have been associated with an increased risk of NEC in preterm neonates [37]. Haiden et al. [29] reported that the administration of oral Gastrografin for meconium evacuation was associated with a higher frequency of NEC in preterm VLBW neonates, although it was not statistically significant. However, it is important to note that this study was not powered to detect such important adverse effects of the intervention. The role of contrast agents such as barium enema is currently limited to evacuation of the meconium plug in neonates [38-41]. Cuenca et al. [38] have reported a spontaneous resolution of $97 \%$ of cases of meconium plug with rectal stimulation or contrast barium enema treatment.

The 2 currently ongoing trials comparing glycerine suppository versus no intervention $(n=250)$ and another trial comparing glycerine suppository versus rectal washouts $(n=60)$ are expected to provide important data (table 3). Pending the results of these studies, other strategies, such as probiotic or prebiotic supplementation to stimulate gastrointestinal maturity and function in preterm VLBW neonates, could also be evaluated [42-47]. Systematic reviews of RCTs have shown that prophylactic 
probiotic supplementation can significantly reduce the risk of NEC $\geq$ stage II and all-cause mortality while facilitating feed tolerance in preterm VLBW neonates [44, $48,49]$. Prebiotic oligosaccharides can modulate electrical activity and gastric emptying and may improve feed tolerance in preterm neonates $[43,46]$. They can also significantly reduce the stool viscosity and accelerate gastrointestinal transport in preterm neonates [47].

In summary, the limited, low-quality evidence indicates that strategies such as prophylactic glycerine suppository, small-volume glycerine/normal saline enema or oral osmotic contrast agents do not reduce the TFF by facilitating meconium evacuation in preterm neonates. These findings will help in designing a large definitive RCT to address this important clinical issue. Such a trial should assess the rectal mode of intervention (glycerine suppository or enema) versus no intervention, preferably in neonates $<28$ weeks of gestation, considering that they are at high risk of feed intolerance. A total of 480 such neonates need to be recruited in such a trial to detect a $20 \%$ reduction in the duration of TFF (mean \pm SD $14 \pm$ 10 days) from baseline, with $80 \%$ power $(\alpha<0.05)$, assuming a $20 \%$ loss to follow-up.

\section{Disclosure Statement}

All authors declare that there is no conflict of interest involved. This research received no specific grant from any funding agency in the public, commercial or not-for-profit sectors.

\section{References}

1 Morris BH, Miller-Loncar CL, Landry SH, Smith KE, Swank PR, Denson SE: Feeding, medical factors, and developmental outcome in premature infants. Clin Pediatr 1999;38: 451-457.

2 Leaf A: Introducing enteral feeds in the highrisk preterm infant. Semin Fetal Neonatal Med 2013;18:150-154.

3 Bisset WM, Watt J, Rivers RP, Milla PJ: Postprandial motor response of the small intestine to enteral feeds in preterm infants. Arch Dis Child 1989;64:1356-1361.

4 McClure RJ, Newell SJ: Randomised controlled trial of trophic feeding and gut motility. Arch Dis Child Fetal Neonatal Ed 1999; 80:F54-F58.

5 Shim SY, Kim HS, Kim DH, Kim EK, Son DW, Kim BI, et al: Induction of early meconium evacuation promotes feeding tolerance in very low birth weight infants. Neonatology 2007;92:67-72.

6 Lucas A, Bloom SR, Aynsley-Green A: Gut hormones and 'minimal enteral feeding'. Acta Paediatr Scand 1986;75:719-723.

7 Berseth CL: Effect of early feeding on maturation of the preterm infant's small intestine. J Pediatr 1992;120:947-953.

8 Berseth CL, Nordyke C: Enteral nutrients promote postnatal maturation of intestinal motor activity in preterm infants. Am J Physiol 1993;264:G1046-G1051.

9 McGuire W, Henderson G, Fowlie PW: Feeding the preterm infant. BMJ 2004;329:12271230.

10 Enriquez A, Bolisetty S, Patole S, Garvey PA, Campbell PJ: Randomised controlled trial of cisapride in feed intolerance in preterm infants. Arch Dis Child Fetal Neonatal Ed 1998; 79:F110-F113.
11 Stenson BJ, Middlemist L, Lyon AJ: Influence of erythromycin on establishment of feeding in preterm infants: observations from a randomised controlled trial. Arch Dis Child Fetal Neonatal Ed 1998;79:F212-F214.

12 Mihatsch WA, Franz AR, Lindner W, Pohlandt F: Meconium passage in extremely low birthweight infants and its relation to very early enteral nutrition. Acta Paediatr 2001;90: 409-411.

13 Patole S, Muller R: Enteral feeding of preterm neonates: a survey of Australian neonatologists. J Matern Fetal Neonatal Med 2004;16: 309-314.

14 Paediatric Formulary Committee: BNF for Children 2010-2011. London, BMJ, 2010.

15 Anabrees J, Shah VS, Al Osaimi A, Al Faleh K: Glycerin laxatives for prevention or treatment of feeding intolerance in very low birth weight infants (review). Cochrane Database Syst Rev 2015;9:CD010464.

16 Livingston MH, Shawyer AC, Rosenbaum PL, Williams C, Jones SA, Walton JM: Glycerin enemas and suppositories in premature infants: a meta-analysis. Pediatrics 2015;135: 1093-1106.

17 Shah V, Chirinian N, Lee S; EPIQ Evidence Review Group: Does the use of glycerin laxatives decrease feeding intolerance in preterm infants? Paediatr Child Health 2011;16:e68-e70.

18 Lefebvre C, Manheimer E, Glanville J: Searching for studies; in Higgins JPT, Green S (eds): Cochrane Handbook for Systematic Reviews of Interventions, version 5.1.0. London, Cochrane Collaboration, 2011.

19 Liberati A, Altman DG, Tetzlaff J, Mulrow C, Gøtzsche PC, Ioannidis JP, et al: The PRISMA statement for reporting systematic reviews and meta-analyses of studies that evaluate healthcare interventions: explanation and elaboration. BMJ 2009;339:b2700.
20 Bell MJ, Ternberg JL, Feigin RD, Keating JP, Marshall R, Barton L, et al: Neonatal necrotizing enterocolitis: therapeutic decisions based upon clinical staging. Ann Surg 1978;187:1-7.

21 Higgins JPT Altman DG, Sterne JAC: Assessing risk of bias in included studies; in Higgins JPT, Green S (eds): Cochrane Handbook for Systematic Reviews of Interventions, version 5.1.0. London, Cochrane Collaboration, 2011.

22 Egger M, Davey Smith G, Schneider M, Minder C: Bias in meta-analysis detected by a simple, graphical test. BMJ 1997;315:629-634.

23 Guyatt GH, Oxman AD, Santesso N, Helfand M, Vist G, Kunz R, et al: GRADE guidelines: 12. Preparing summary of findings tables binary outcomes. J Clin Epidemiol 2013;66: 158-172.

24 Khadr SN, Ibhanesebhor SE, Rennix C, Fisher HE, Manjunatha CM, Young D, et al: Randomized controlled trial: impact of glycerin suppositories on time to full feeds in preterm infants. Neonatology 2011;100:169-176.

25 Haiden N, Jilma B, Gerhold B, Klebermass K, Prusa AR, Kuhle S, et al: Small volume enemas do not accelerate meconium evacuation in very low birth weight infants. J Pediatr Gastroenterol Nutr 2007;44:270-273.

26 Mena NP, Leon del PJ, Sandino PD, Ralmolfo BP, Sabatelli D, Llanos MA, et al: Meconium evacuation to improve feeding tolerance in very low birth weight preterm infants (Emita Protocol) (in Spanish). Rev Chil Pediatr 2014; 85:304-311.

27 Shinde S, Kabra NS, Sharma SR, Avasthi BS, Ahmed J: Glycerin suppository for promoting feeding tolerance in preterm very low birthweight neonates: a randomized controlled trial. Indian Pediatr 2014;51:367-370. 
28 Saenz de Pipaón Marcos M, Teresa Montes Bueno M, Sanjose B, Gil M, Parada I, Amo P: Randomized controlled trial of prophylactic rectal stimulation and enemas on stooling patterns in extremely low birth weight infants. J Perinatol 2013;33:858-860.

29 Haiden N, Norooz F, Klebermass-Schrehof K, Horak AS, Jilma B, Berger A, et al: The effect of an osmotic contrast agent on complete meconium evacuation in preterm infants. Pediatrics 2012;130:e1600-e1606.

30 Hozo SP, Djulbegovic B, Hozo I: Estimating the mean and variance from the median, range, and the size of a sample. BMC Med Res Methodol 2005;5:13.

31 Sterne JA, Sutton AJ, Ioannidis JP, Terrin N, Jones DR, Lau J, et al: Recommendations for examining and interpreting funnel plot asymmetry in meta-analyses of randomised controlled trials. BMJ 2011;343:d4002.

32 Jadcherla SR, Kliegman RM: Studies of feeding intolerance in very low birth weight infants: definition and significance. Pediatrics 2002; 109:516-517.

33 Neu J: Gastrointestinal maturation and implications for infant feeding. Early Hum Dev 2007;83:767-775.

34 Berseth CL: Gastrointestinal motility in the neonate. Clin Perinatol 1996;23:179-190.

35 Pearson F, Johnson MJ, Leaf AA: Milk osmolality: does it matter? Arch Dis Child Fetal Neonatal Ed 2013;98:F166-R199.
36 Barness LA, Mauer AM, Holliday MA, et al: Commentary on breast-feeding and infant formulas, including proposed standards for formulas. Pediatrics 1976;57:278-285.

37 Travadi J, Patole S, Simmer K: Gastrointestinal contrast studies in high-risk neonates with suspected necrotising enterocolitis - a note of caution. J Perinatal Med 2003;31:523-525.

38 Cuenca AG, Ali AS, Kays DW, Islam S: 'Pulling the plug' - management of meconium plug syndrome in neonates. J Surg Res 2012; 175:e43-e46.

39 Keckler SJ, St Peter SD, Spilde TL, Tsao K, Ostlie DJ, Holcomb GW 3rd, et al: Current significance of meconium plug syndrome. J Pediatr Surg 2008;43:896-898.

40 Siddiqui MM, Drewett M, Burge DM: Meconium obstruction of prematurity. Arch Dis Child Fetal Neonatal Ed 2012;97:F147-F150.

41 Noblett HR: Treatment of uncomplicated meconium ileus by gastrografin enema: a preliminary report. J Pediatr Surg 1969;4:190197.

42 Athalye-Jape G, Rao S, Patole S: Lactobacillus reuteri DSM 17938 as a probiotic for preterm neonates: a strain-specific systematic review. J Parenter Enteral Nutr 2015, Epub ahead of print.
43 Indrio F, Riezzo G, Raimondi F, Bisceglia M, Bisceglia M, Cavallo $\mathrm{L}$, et al: The effects of probiotics on feeding tolerance, bowel habits, and gastrointestinal motility in preterm newborns. J Pediatr 2008;152:801-806.

44 Athalye-Jape G, Deshpande G, Rao S, Patole $S$ : Benefits of probiotics on enteral nutrition in preterm neonates: a systematic review. Am J Clin Nutr 2014;100:1508-1019.

45 Indrio F, Riezzo G, Raimondi F, Bisceglia M, Cavallo L, Francavilla R: Effects of probiotic and prebiotic on gastrointestinal motility in newborns. J Physiol Pharmacol 2009;60 (suppl 6):27-31.

46 Indrio F, Riezzo G, Raimondi F, Francavilla R, Montagna O, Valenzano ML, et al: Prebiotics improve gastric motility and gastric electrical activity in preterm newborns. J Pediatr Gastroenterol Nutr 2009;49:258-261.

47 Mihatsch WA, Hoegel J, Pohlandt F: Prebiotic oligosaccharides reduce stool viscosity and accelerate gastrointestinal transport in preterm infants. Acta Paediatr 2006;95:843848

48 Deshpande G, Rao S, Patole S: Probiotics for prevention of necrotising enterocolitis in preterm neonates with very low birthweight: a systematic review of randomised controlled trials. Lancet 2007;369:1614-1620.

49 Al Faleh K, Anabrees J: Probiotics for prevention of necrotizing enterocolitis in preterm infants. Evid Based Child Health 2014;9:584671
Meconium Evacuation for Facilitating Feed Tolerance in Preterm Neonates 